\title{
Entre el common law y el civil law de finales del siglo XIX. Racionalidad del derecho y previsibilidad en Weber(*)
}

\author{
Between the common law and the civil law of the late 19th century. \\ Rationality of law and predictability in Weber
}

\author{
Luiz Guilherme Marinoni ${ }^{[*]}$
}

\begin{abstract}
Resumen: en las dos versiones del libro "La ética protestante y el espíritu del capitalismo", Weber, pretende dejar en claro que, así como los valores del protestantismo dieron origen a un modo de vivir que se identificó en el «espíritu» del capitalismo y contribuyeron a su desarrollo, se puede afirmar que dichos valores favorecieron un modo de vida racional y la racionalización del derecho.

Sin embargo, Weber no identificó dicha racionalidad jurídica formal con previsibilidad, sino que, por el contrario, vio en el stare decisis un mecanismo capaz de propiciar previsibilidad a un derecho formalmente irracional, de tal forma que el common law, fuera capaz de garantizar, mediante el sistema de los precedentes obligatorios, un grado de previsibilidad que permitió el nacimiento del capitalismo. Constituyendo así, la oportunidad que Weber ofrece para demostrar que el stare decisis es un instrumento para lograr la previsibilidad en el derecho.
\end{abstract}

Palabras claves: racionalidad, derecho, previsibilidad, capitalismo, protestantismo.

Abstract: in the two versions of the book "The Protestant Ethics and the Spirit of Capitalism", Weber intends to make it clear that, just as the values of Protestantism gave rise to a way of life that was identified in the «spirit» of capitalism and contributed to its development, it can be said that those values favoured a rational way of life and the rationalization of law.

However, Weber did not identify such formal legal rationality with predictability, but, on the contrary, saw in stare decisis a mechanism capable of providing predictability to a

[*] El artículo fue originalmente presentado en: Marinoni, Luiz. (2018). Entre el common law y el civil law de finales del siglo XIX. Racionalidad del derecho y previsibilidad en weber. Revista de Ciencias Sociales, número 12. DOI 10.22370/rcs.2018.72.2177.

https://www.researchgate.net/publication/341629805_ENTRE_EL_COMMON_LAW_Y_EL_CIVIL_LAW_DE_FINALES_DEL_SIGLO_XIX_RACIONALIDAD_DEL_DERECHO_Y_PREVISIBILIDAD_EN_WEBER

[**] Profesor Catedrático de la Universidad Federal del Paraná - Brasil. Contacto: guilherme@marinoni.adv.br 
formally irrational right, in such a way that common law, was able to guarantee, through the system of binding precedents, a degree of predictability that allowed the birth of capitalism. Thus constituting the opportunity offered by Weber to demonstrate that stare decisis is an instrument to achieve predictability in law.

Key words: rationality, right, predictability, capitalism, protestantism.

\section{PROTESTANTISMO, ASCESIS INTRAMUN- DANA, RACIONALIDAD Y CAPITALISMO}

Entre 1904 y 1905, Weber publica las dos partes de la primera versión de su clásico libro La ética protestante y el espíritu del capitalismo. Se podría decir que el autor «completa» esta primera versión, en 1920, poco antes de su muerte, con importantes ampliaciones y sólidas notas, destinadas a aclararla y dar una respuesta a las críticas recibidas. Al respecto, Pierucci (2005) afirma:

Weber no nos dejó dos ediciones de La ética protestante, sino dos versiones. La primera, publicada en dos tomos, en 1904 y 1905, y la segunda, revisada y ampliada, en 1920. Todas las traducciones hasta hoy conocidas, empezando por la primera, de 1930, de Talcott Parsons, lo fueron de la versión ampliada de 1920, que Weber incluye en el volumen I de los Ensayos sobre la sociología de la religión. Hay diferencias importantes entre ambas versiones, pues, en la segunda, el autor no solo introdujo pequeñas modificaciones y ajustes terminológicos o gramaticales, sino que principalmente la amplió con aportaciones muy valiosísimas. (p. 187)

El propósito de Weber es demostrar que el modo de vida de los protestantes, entre quienes incluye a los calvinistas, los luteranos, los metodistas, los menonitas y los cuáqueros, contribuyó al desarrollo del capitalismo. En un principio, el libro relaciona el progreso económico con la población protestante, a fin de demostrar que existe un claro vínculo entre las doctrinas religiosas protestante y católica, la elección de la profesión y el consecuente destino profesional. Weber (2004), señala:

Los artesanos católicos tienen una tendencia más acentuada a mantenerse en la arte- sanía, convirtiéndose así con más frecuencia en maestros artesanos, mientras que los protestantes desembocan en mayor medida en las fábricas, para ocupar en ellas los niveles superiores del proletariado cualificado y de los puestos administrativos. (pp. 32-33)

Señala que el interés de los católicos se centraba en los gymnasien humanísticos, mientras que los protestantes preferían los centros orientados a preparar para profesiones comerciales e industriales, es decir, para la vida de los negocios. Este fenómeno no puede justificarse en la diferencia de fortunas, pero explicaría el escaso interés que los católicos exteriorizaban por la adquisición capitalista.

En el segundo capítulo de la parte I, Weber se refiere a lo que denomina «espíritu» del capitalismo. Alude a un texto de Benjamín Franklin de que se extrae la idea de «profesión como deber» y de «ganancia de dinero» como resultado y expresión de la habilidad profesional. Las máximas de Franklin, que recomienda el trabajo duro y sistemático, junto con la austeridad, sintetizarían el «espíritu del capitalismo». Según Weber (2004a), se trata de una «ética» cuya violación representa el incumplimiento de un deber.

De hecho, aquí no se predica simplemente una técnica de vida, sino una «ética» peculiar cuya violación no se considera solo un desacierto, sino una especie de omisión del deber: esto, ante todo, es la esencia de la cosa. No solo se enseña a tener «perspicacia en los negocios" - lo que es bastante frecuente-, sino un ethos que se manifiesta, y es justamente esta condición la que nos interesa. (p. 45)

Así, en este contexto cultural, surge la idea, en la actualidad trivial, de «profesión 
como deber», elemento constitutivo del capitalismo. (Weber, 2004a, p. 47)

El tercer capítulo se refiere al concepto luterano de «vocación». Este concepto, presente en las expresiones beruf y calling, se relaciona con la idea de trabajo como misión dada por Dios. Se pretende probar que los protestantes, al contrario de los católicos, rechazaron la ascesis monástica (vista como ascesis extramundana) como medio de salvación, pues consideraban que el estricto cumplimiento de los deberes intramundanos era el único medio de vivir agradable a los ojos de Dios. En esta línea, Weber (2004a), señala que:

Así, en el concepto de beruf (profesión) se expresa cada vez con mayor intensidad aquel dogma central de todas las tendencias protestantes que rechaza la distinción católica de los mandatos morales en praecepta y consilia y reconoce como único medio de vivir que agrada a Dios no aquel que suplanta la moralidad intramundana mediante la ascesis monástica, sino el que cumple los deberes intramundanos derivados de la posición del individuo en la vida, que de este modo se convierte en su «Vocación profesional». (p. 72)

Según el protestantismo, la glorificación de Dios debería producirse en las cosas cotidianas, no en la reclusión de una vida monacal. De este modo, uno de los efectos de la Reforma fue el deber de ejercer bien la profesión. De ahí deriva la idea luterana de «vocación profesional»y, en particular, la relación entre un modo de vivir influenciado por el protestantismo, más concretamente, por el calvinismo, y el «espíritu» del capitalismo.

La enseñanza reformista fue la que, por primera vez, proclamó que la actividad profesional y la función social tenían un valor no solo moral, sino también esencialmente religioso. Lo que agrada a Dios no es el ascetismo de los monjes, sino, todo lo contrario, el ejercicio concienzudo de todas las actividades profesionales y seculares que el hombre realiza en la vida diaria. Es para la minuciosa ejecución de estas tareas profanas que Dios llama al hombre, estas son el objeto de su vocación. (Biéler, 2012, p. 586)

En el primer capítulo de la parte II, Weber trata de los «fundamentos religiosos de la ascesis intramundana». Es decir, de los valores de la religión protestante que llevaron a la idea de que la devoción a Dios debe demostrarse mediante prácticas y comportamientos cotidianos, como la búsqueda de la perfección en el ejercicio de la profesión. La ascesis intramundana parte de la premisa de que el trabajo es un deber religioso que tiene que ejercerse con rigurosa disciplina. Se caracteriza como medio ideal para que el cristiano cumpla, «en el mundo», el deseo divino. En este sentido, Weber habla de «protestantismo ascético» y, con cautela, considera los contenidos de los valores primordiales del calvinismo, el pietismo, el metodismo y los movimientos anabaptistas de modo a evidenciar y caracterizar los fundamentos religiosos de la ascesis intramundana.

De este modo, Weber advierte, con relación al calvinismo, que la doctrina de la predestinación —el hombre no puede hacer nada para salvarse, pues la condena o salvación del hombre depende de la decisión divina- es un fundamento dogmático de la moralidad puritana en el sentido de una conducta de vida ética metódicamente racionalizada. Weber demuestra que el calvinismo rechazó los medios sacramentales de salvación característicos del catolicismo, en particular, la salvación por medio de obras o la confesión, para centrarse en la conducta intramundana, en concreto, en el trabajo profesional, medio de acción que daría al calvinista la demostración de su elección ${ }^{[1]}$.

[1] «y, por otro lado, se distingue el trabajo profesional sin descanso como el medio más destacado para lograr esa confianza en sí mismo. Él, y solamente él, disiparía la duda religiosa y daría la certeza del estado de gracia» (Weber, 2004a, p. 102). 
La preocupación calvinista con la corrección de la conducta y el adecuado ejercicio de las tareas cotidianas, necesarios para comprobar su salvación, estimuló un control metódico de la orientación de la vida. De acuerdo con Weber, esta racionalización de la conducta de vida mundana, sin perder de vista el «otro mundo», es el resultado de la concepción que el protestantismo ascético tiene de la profesión.

Esta ascesis ya no suponía un opus supererogationis, sino que era una realización que se exigía a todo aquel que quisiera estar seguro de su bienaventuranza. Esta singular vida de los santos, que exigía la religión y se diferenciaba de la vida «natural», no se proyectaba - y esto es lo fundamental - fuera del mundo en comunidades monásticas, sino dentro del mundo y sus órdenes. Esta racionalización de la conducta de vida en el mundo pero con la mirada puesta en el más allá es el resultado de la concepción que el protestantismo ascético tiene de la profesión. (Weber, 2004a, p. 139)

En el último capítulo, Weber relaciona la ascesis del protestantismo con el «espíritu» del capitalismo. Demuestra que entender el trabajo como un deber religioso, como medio para comprobar la fe y la propia elección, fue un poderoso impulso para una vida marcada por el «espíritu» capitalista. El trabajo sistemático y continuo, del que surgen ganancias de modo natural, ayudó al desarrollo del capitalismo, pues justamente representa una manera adecuada de glorificar a Dios en el mundo. El lucro sería el resultado de una conducta de vida sistemática, incluso en el trabajo, por lo que era una forma adecuada de honrar a Dios. Pero la ascesis protestante no solo rompió las amarras que impedían la obtención de beneficios, sino que también condenó el disfrute relajado de las posesiones, con lo que estranguló el consumo frívolo, especialmente del lujo, cuya consecuencia fue, según Weber, la acumulación de capital mediante la coerción ascética al ahorro.
La ascesis protestante intramundana - para resumir todo lo dicho hasta este momentoobró de esta forma, con toda la vehemencia, contra el disfrute relajado de las posesiones; estranguló el consumo, en particular, el consumo del lujo. En compensación, tuvo el efecto psicológico de liberar al enriquecimiento de las trabas de la ética tradicional, rompió las cadenas que rodeaban a la ambición de lucro, no solo al legalizarlo, sino también al enfrentarlo (en el sentido descrito) como directamente querido por Dios (...). $Y$ enfrentado ahora ese estrangulamiento del consumo con esa desobstrucción de la ambición de lucro, el resultado es evidente: acumulación de capital mediante coerción ascética al ahorro. (Weber, 2004a, pp. 155-157)

La relación entre la ascesis, derivada del calvinismo, con el «espíritu» del capitalismo, pasa por la racionalización de la conducta humana. La ascesis intramundana o el ejercicio del trabajo como deber religioso no solo está claramente conectado con la racionalización del control de la dirección de la vida, sino que constituye una forma racional de ver la salvación, en la medida en que esta, para los seguidores de la doctrina de la predestinación, nunca podría depender de medios mágicos o sacramentales - como las obras-, sino solo exigir comprobación mediante el control racional del desempeño profesional o de los actos de la vida intramundana.

El rechazo a los sacramentos, vistos como magia, y a la concepción de que solo la perseverancia en una conducta orientada a la glorificación de Dios o a la búsqueda de señales de la elección, llevó a Weber, en la segunda versión de La ética protestante y el espíritu del capitalismo, a aludir al «desencantamiento del mundo». Weber se refiere a un proceso histórico de desmagificación de la salvación y de racionalización de la vida en occidente.

Como señala Pierucci (2005), uno de los más importantes estudiosos sobre Weber de las últimas décadas: 
El término desencantamiento entendido como desmagificación asume la dimensión de un «gran» proceso histórico que es específicamente ético-religioso y occidental, y así pretende designar, casi a modo de nombre propio y no común, el larguísimo período de peculiar racionalización religiosa por el que pasó, a merced de motivos puramente históricos [rein historisch], la religiosidad occidental bajo la hegemonía cultural alcanzada por esta forma «característicamente moralizada» de fe monoteísta represora de la magia universal llamada judeocristianismo. Sus creadores y primeros portadores [Träger] fueron los profetas de Israel, florón del judaísmo antiguo; y fueron las sectas protestantes sus radicales y firmes portadores [Träger] en la época heroica del parto cultural de la moderna civilización del trabajo, su punto de llegada religioso. (p. 199)

Como explica el enfoque de Pierucci (2005), «desencantamiento-desmagificación» y «etización-moralización» son dos caras de una misma moneda o dos aspectos de un mismo proceso histórico-religioso que caracteriza la orientación de la racionalización social y cultural de Occidente, conformando su carácter específico de racionalización vivida como trabajo racional.

El desencantamiento del mundo o la desmagificación de la salvación se relacionan con la ascesis intramundana y el ejercicio del trabajo impregnados por los valores del protestantismo, que llevarían a una forma de vida racional y orientada a fines. Se trata de una forma peculiar de racionalización, derivada de valores religiosos. Por tanto, no se puede pensar en desencantamiento como (sinónimo de) racionalización, como si esta última no pudiera tener otro origen o intensidad o, en definitiva, como si la racionalización que lleva a cabo el desencantamiento del mundo no fuera una particular racionalización del modo de vida en virtud de un motivo concreto, pues el proceso de la racionalización, según Weber, se produce de forma distinta en las múltiples esferas de la vida social.
Como es sabido, el contenido del calvinismo está fuertemente marcado por la doctrina de la predestinación, tal como se refleja en la Confesión de Fe de Westminster, de 1647, en la que se señala que, «por decreto divino, para la manifestación de su propia gloria, algunos hombres y ángeles son predestinados (predestinated) a vida eterna, y otros preordenados (foreordained) a muerte eterna» (Capítulo III, n.으 3). Además: «A aquellos que Dios ha predestinado para vida desde antes que fuesen puestos los fundamentos del mundo, conforme a su eterno e inmutable propósito y al consejo y beneplácito secreto de su propia voluntad, los ha escogido en Cristo para la gloria eterna. Dios los ha predestinado por su libre gracia y puro amor, sin previsión de su fe o buenas obras, de su perseverancia en ellas o de cualquiera otra cosa en la criatura como condiciones o causas que le muevan a predestinarlos; y lo ha hecho todo para alabanza de su gloriosa gracia». (Capítulo III, n.으)

El calvinista, al aceptar la doctrina de que determinados hombres fueron elegidos o salvados antes de que la humanidad llegara al mundo, no podía buscar la salvación durante su vida, bien fuera por medio de obras o sacramentos, sino solo intentar encontrar la comprobación de que había sido elegido por Dios. Como afirma Biéler (2012):

Ahora bien, lo que -en los países en los que el capitalismo y la cultura estaban más desarrollados, la Holanda, la Inglaterra y la Francia de los siglos XVI y XVII-, caracterizó, de manera más típica, a las iglesias y las sectas calvinistas, en la época en la que eran combatidas con más vehemencia, es su dogma de la predestinación. En torno a este dogma se produjeron las luchas eclesiásticas más violentas de los siglos XVII y XVIII; es, por tanto, este el que debe considerarse como el más específico dogma de la fe calvinista. Este, para un reformado (afirma Weber), da sentido a todos los actos de la vida, incluso los a los más insignificantes. El hombre no 
vive para sí, sino para honrar a Dios, soberano único, los decretos de quien determinan toda la historia de la humanidad y deciden la salvación de cada sujeto. (p. 588)

Weber se pregunta cómo fue posible soportar esta doctrina en una época en la que el «más allá» era más importante y, en diversos aspectos, también más seguro que los intereses de la vida en este mundo.

Ahora bien, el problema decisivo para nosotros es, ante todo, saber cómo se soportó esta doctrina en una época en la que el más allá era no solo más importante, sino en muchos aspectos también más seguro que los intereses de la vida en este mundo». (Weber, 2004a, p. 100).

Como la incertidumbre de la elección provocaba una extrema angustia, Weber señala que el trabajo profesional sin descanso fue considerado como el medio más importante para conseguir la confianza en sí mismo en la elección, visto como la única forma de disipar la duda religiosa y dar la certeza del estado de gracia.

Como el trabajo sistemático ayuda a comprobar la elección, es natural que la responsabilidad personal adquiera una gran relevancia. El calvinista, al sentir el peso del «deber de la profesión», no puede dejar de cumplir las obligaciones inherentes a ella. No existe tan solo el deber de cumplir bien la «misión profesional», sino también el deber de cumplir las obligaciones derivadas del ejercicio de la profesión. Tanto olvidar el riguroso y continuo ejercicio de la profesión, como no pagar una deuda, son indicios de falta de elección. El ejercicio de la profesión y el cumplimiento de las obligaciones como deber religioso le generan al calvinista un extremo rigor consigo mismo, es decir, una inspección de su conducta profesional y personal inflexible y continua. La comprobación de la elección, como no tiene que ver con la realización de obras meritorias aisladas, es decir, con obras para la salvación (Biéler, 2012, p. 590), exigía un continuo y sistemático exa- men de uno mismo, que propiciara la «certeza» de haber sido elegido. Weber, citado por Weber (2004a) señala que:

La supresión de la magia como medio de salvación, no se llevó a cabo en la piedad católica con los mismos resultados que en la piedad puritana ( $y$, con anterioridad, en la judía). Los católicos disponían de la gracia sacramental de su Iglesia como medio para compensar su propia insuficiencia: el sacerdote era un mago que realizaba el milagro de la transformación y en cuyas manos tenía las llaves del poder. Se podía acudir a él con arrepentimiento y contrición, que él imponía penitencias e infundía la esperanza de la gracia, la certeza del perdón y, de ese modo, aliviaba la enorme aflicción, en la que vivía el calvinista como si fuera el destino implacable del que no podía redimirse. Para él no había consuelo afectivo ni humano, tampoco podía albergar la pretensión de compensar los momentos de debilidad e imprudencia, mediante la buena voluntad, como sí podían los católicos y los luteranos. A los calvinistas, Dios les exigía, no «buenas obras» aisladas, sino una santidad sistemática en el obrar. [No se piensa en el vaivén católico y auténticamente humano entre pecado, arrepentimiento, penitencia, alivio $y$, de nuevo, pecado, ni tampoco en ese saldo de la vida entera que se purifica mediante castigos temporales o la intervención eclesiástica de la gracia]. La praxis ética del hombre común se despojó, de este modo, de su falta de visión de conjunto y sistematicidad, para convertirse en un método coherente de comportamiento global. No es una casualidad que se diera el sobrenombre de «metodistas» a los causantes del último gran resurgimiento de ideas puritanas en el siglo XVIII, de igual manera que en el siglo XVII se aplicó a sus predecesores espirituales el calificativo de «precisistas». (pp. 106-107)

Por tanto, la idea de deber profesional, fuertemente marcada por la responsabilidad -resultante de la necesidad de comprobar la elección-, consiste en un modo de vivir do- 
tado de racionalidad. La búsqueda de la comprobación de la elección en los actos de la vida intramundana, en particular, en el ejercicio de la profesión, no podía darse sin un método que permitiera el control racional de la acción humana. Para que esta pudiera generar los mejores resultados era imprescindible la previsibilidad, sin la que el sujeto no podría saber si sus actos producirían efectos positivos.

El control racional de la propia conducta exige saber cómo será evaluada la acción humana, es decir, implica poder prever los resultados de las acciones y los acontecimientos. La falta de previsibilidad acaba con cualquier posibilidad de conducta metódica en el ejercicio de la profesión.

Cuando se piensa en el ejercicio óptimo de la profesión como forma de santificación o exteriorización de la elección, no es suficiente con preguntarse por la adecuación de la acción a las reglas religiosas, sino que hay que comprobar si la acción puede lograr un resultado que agrade a Dios. Para ello, las reglas que regulan la vida del individuo tienen que ser previsibles. Así, para poder ejercer la profesión de forma adecuada, es imprescindible la previsibilidad del derecho, de modo que se obtenga un resultado que sea señal de elección. Sin previsibilidad, el individuo no puede saber si su acción metódica le permitirá lograr los resultados deseados. La religión representa así un estímulo para el adecuado ejercicio de la profesión y la obtención de un resultado óptimo, evidentemente, no un indicio o señal de la consecución de dicho resultado. Es decir, los valores del protestantismo, al igual que tienen una íntima relación con el «espíritu» del capitalismo, también pueden asociarse a la racionalidad del derecho.

\section{RACIONALIDAD DEL DERECHO, CAPITA- LISMO Y RELIGIÓN}

Para el desarrollo del capitalismo era imprescindible un derecho racional y previsible. Weber en El origen del capitalismo moderno, en la versión de Souza (2006) tras recordar la completa irracionalidad del derecho chino primitivo, afirma que, con un derecho de esa naturaleza, «el capitalismo no puede funcionar. Lo que este necesita es un derecho que pueda calcularse, similar a una máquina. Los aspectos religioso-rituales y mágicos no tienen ningún valor» (p. 95). Aludiendo a este fragmento de Weber, Jessé Souza (2006) afirma que «Weber percibe el derecho racional formal como fundamental para la existencia del capitalismo moderno, por su naturaleza calculable y su previsibilidad. No se pueden planificar ni calcular a largo plazo actividades imprescindibles para la existencia de un mercado competitivo, basado en principios impersonales, cuando la justicia depende de presupuestos mágicos, como en este fragmento concreto, en el que pone el ejemplo de la sociedad china o de la discrecionalidad de los jueces que deciden según su propio arbitrio» (p. 95). Swedberg (2005) también recuerda que el planteamiento weberiano sobre la sociología económica da una atención especial al derecho y enfatiza en que «uno de los presupuestos del capitalismo racional occidental, según Weber, «es una ley racional, es decir, previsible»»' (p. 155).

No hay duda de que, para Weber, existe una íntima relación entre racionalidad del derecho y capitalismo, así como una clara conexión entre protestantismo ascético y capitalismo. Sin embargo, es necesario investigar si es posible asociar protestantismo y racionalidad del derecho.

Como es obvio, nunca se ha pretendido afirmar que, si no hubiera sido por los valores calvinistas, el capitalismo no se hubiera desarrollado, sino más bien que dichos valores contribuyeron a la existencia de un comportamiento social - la ascesis intramundana-que constituyó el «espíritu» capitalista y, por consiguiente, contribuyó a su desarrollo. Por otro lado, el desarrollo del capitalismo dependía de la racionalidad y la previsibilidad del derecho.

Sin embargo, no hay razón para asociar únicamente protestantismo a capitalismo, pues la racionalidad del derecho fue una pre- 
misa para el desarrollo del capitalismo sobre la que aquel no influyó. Como ya se ha señalado, el protestantismo también sirvió para definir una vida metódica y dotada de racionalidad. La acción del individuo, precisamente por no poder desvincularse de un fin o resultado óptimo como comprobación de la elección, constituía una acción racional, que no podía ignorar la previsibilidad. De modo que la vida pautada por la ascesis intramundana, característica del calvinismo, también exigía un derecho racional y marcado por la previsibilidad. Cabe subrayar que Weber (2004b) señala que los protestantes - que formaban parte de la estructura burguesa - tenían interés en que el derecho fuera calculable.

Naturalmente, cabe sobre todo a los interesados burgueses exigir un derecho inequívoco, claro, sin arbitrio administrativo irracional ni perturbaciones irracionales de privilegios concretos: un derecho que, ante todo, garantice de forma segura el carácter jurídicamente obligatorio de contratos y que, en virtud de todas esas cualidades, funcione de modo calculable. (p. 123)

Es evidente que no se pretende hacer creer que la causa, ni siquiera la causa principal, de la racionalidad del derecho es el protestantismo ascético. Weber no solo creía que el derecho europeo era más racional que los derechos de otras civilizaciones, sino que también demostró que dicho derecho se modeló a partir de distintas características históricas peculiares del derecho occidental —como la tradición del derecho romano y aspectos del derecho medieval-, y sintió el influjo de distintas y amplias tendencias religiosas, económicas y políticas de la vida occidental (Trubeck, 1972, p. 737).

Por tanto, lo que realmente se pretende dejar claro es que, así como los valores del protestantismo dieron origen a un modo de vivir que se identificó en el «espíritu» del capitalismo y contribuyeron a su desarrollo, se puede afirmar que dichos valores favorecieron un modo de vida racional y la racionalización del derecho. En términos estrictamente weberianos, se puede afirmar que el derecho previsible está en relación de causalidad adecuada con el modo de vida sistemático y metódico que resulta de la ascesis intramundana.

De este modo, si el perfeccionamiento de los negocios es una búsqueda que racionalmente se orienta en valores religiosos y si, para ello, son imprescindibles la racionalidad y la previsibilidad del derecho, es evidente la relación existente entre los valores del calvinismo y la racionalidad del derecho. Aquí entra en juego la idea weberiana de acción social racionalmente determinada con relación a fines y valores. De acuerdo con Weber (2009) la acción social, como toda acción, puede ser determinada: i) de modo racional con arreglo a fines: por expectativas sobre el comportamiento de objetos del mundo exterior y de otras personas, utilizando dichas expectativas como «condiciones» 0 «medios» para lograr fines propios, ponderados y perseguidos de forma racional, como éxito; ii) de modo racional con arreglo a valores: por la creencia consciente en el valor -ético, estético, religioso o cualquiera que sea su interpretación - absoluto e inherente a un determinado comportamiento como tal, con independencia del resultado; iii) de modo afectivo, especialmente emocional: por estados afectivos o emocionales actuales; iv) de modo tradicional: por costumbre arraigada. (p. 15)

El calvinista, para dirigir su vida, se regía por valores religiosos, aunque buscara señales externas de su elección, es decir, resultados que evidenciaran su salvación. De modo que se puede afirmar que el calvinista ejercía una acción social racional con arreglo a un fin -tener éxito en la profesión o los negocios-, pero al mismo tiempo ejercía una acción social racional orientada o también determinada por un valor religioso - la doctrina de la predestinación-. También se podría decir que la acción racional que consiste en el trabajo metódico y sistemático estaría determinada, al mismo tiempo, por un fin y un valor. Pierucci (2005), 
en su tesis sobre el concepto weberiano de «desencantamiento del mundo», afirma que Weber busca mostrar que, con esa coincidencia entre la actividad profesional y la certeza interior de la salvación del alma que se logra mediante el acto de trabajar racionalmente, el protestantismo ascético produjo una unidad inquebrantable y singular entre la acción racional con arreglo a fines [Zweckrationalität] y la acción racional con arreglo a valores [Wertrationalität], de modo que, en otros términos, se habría producido un encaje históricamente inaudito entre la racionalidad práctico-técnica y la racionalidad práctico-ética.

No obstante, si ahí se puede ver una modalidad de acción determinada por un fin y un valor, que completa las condiciones de la racionalidad práctica en su integridad, no se puede dejar de observar que dicha acción, ya sea para lograr el fin o para no ignorar el valor, no puede prescindir de un derecho racional y previsible. Sin duda, la conducta «protestante», además de constituir una acción innegablemente racional, inspirada por un valor religioso y orientado a la obtención de un fin, exigía, para evitar su frustración, un derecho capaz de garantizar el fin o el resultado. El derecho, bien es verdad, no busca garantizar el valor, sino el fin cuya realización origina la concreción del valor. El derecho funciona, en este caso, como instrumento de racionalización de la vida orientada por la religión y dirigida a la consecución de fines.

José Eduardo Faria, en el prólogo a la famosa obra de Anthony Kronman (2009) sobre la sociología jurídica weberiana, afirma que Weber, al estudiar el islamismo, el judaísmo y la China antigua, muestra cómo la historia moderna se caracteriza por la progresiva racionalización de todos los sectores de la vida, donde la eficiencia y el cálculo se han convertido en criterios supremos. La acción racional que de ello deriva, siempre relacionando medios y fines, podría verse como i) acción racional práctica: que implica la elección de medios disponibles y eficientes para lograr un fin; ii) acción racional material: fundada en valores elegidos en función de convicciones personales; y iii) acción racional formal: que exige reglas impersonales, abstractas y generales enlazadas de manera lógica para orientar las conductas sociales.

Tras advertir que, dado que fija marcos referenciales y genera expectativas de su cumplimiento, la acción racional formal es la que ofrece mayor previsibilidad y probabilidad de producirse, Faria enfatiza que «un ejemplo emblemático de racionalidad formal señalado por Weber es el derecho positivo, que el autor ve como un mecanismo que aumenta la probabilidad de que ciertas acciones se produzcan de un modo determinado, es decir, del modo cómo las prescribían los códigos y las leyes. Al garantizar el respeto a la propiedad, asegurar la validez y el cumplimiento de los contratos, ofrecer a los agentes económicos la seguridad que necesitan para invertir e, incluso, hacer previsibles los cambios según sus propias reglas y procedimientos, el derecho positivo funciona como un «mitigador» de la indeterminación de las acciones sociales, como mecanismo que facilita la interacción humana y como marco referencial para las llamadas «reglas del juego». Así, apoyándose en esta línea de razonamiento, Weber explica cómo el pensamiento político, la legislación, la administración de justicia y las prácticas económicas van, en la transición del mundo medieval al moderno, liberándose de todos los grilletes que representan los mitos, los tabús y los misterios, de modo que la separación entre el Dios transcendente y un mundo sin magia termina con el protestantismo de naturaleza calvinista y la consecuente llegada de la modernidad y el capitalismo». (Kronman, 2009)

Recordar el prólogo de José Eduardo Faria tiene el objetivo de demostrar la íntima relación existente entre acción racional orientada a fines e incentivada por valores, propia de la vida marcada por el protestantismo ascético, y la racionalidad del derecho. El ejercicio de la 
profesión por parte del calvinista, una acción dirigida al éxito para la comprobación de la elección y, por ende, también pautada en valor, no podía prescindir de una acción racional formal, esto es, del derecho positivo, única forma capaz de garantizar las expectativas puestas en la energía que emana del trabajo. Es decir, única manera de justificar el propio ejercicio de la profesión como mecanismo de comprobación de la predeterminación de la elección.

En resumen, la ascesis intramundana o, más concretamente, el ejercicio del trabajo como medio para comprobar la salvación, no es más que una clara expresión del «desencantamiento con el mundo», derivado de la ruptura con la magia de los sacramentos de salvación, una ascesis que consistía en una acción racional impulsada por valores y dirigida a fines. Por ello, dicha ascesis no podía prescindir de un mecanismo —el derechoque, con claridad y lógica, fuera adecuado para garantizar el resultado de la energía y el valor depositado en los actos de la vida.

\section{RACIONALIDAD DEL DERECHO Y PREVI- SIBILIDAD}

Otro punto relevante se refiere al significado que para Weber tiene la racionalidad del derecho y si, según el autor, hay distinción entre racionalidad formal del derecho y previsibilidad. Weber alude a cuatro tipos ideales de derecho: i) derecho formalmente irracional; ii) derecho sustancialmente irracional; iii) derecho sustancialmente racional; y iv) derecho formalmente racional.

A pesar de que lo realmente importante, en este contexto, sea constatar lo que Weber entendía por derecho formalmente racional, conviene recordar que los escritos sobre la teoría de Weber advierten que los referidos tipos ideales de derecho corresponden, aunque de manera no exacta, a las cuatro fases de la evolución histórica del derecho de las que trata la obra weberiana. (Swedberg, 2005, p. 166)
La creación y la aplicación del derecho pueden ser racionales o irracionales. Son formalmente irracionales cuando, para regular la creación del derecho y sus problemas de aplicación, se utilizan medios que no pueden ser racionalmente controlados, como, por ejemplo, la consulta a oráculos y sus sucedáneos. (Weber, 2004b, p. 12)

En primer lugar, el derecho formalmente irracional, no controlado por el intelecto, contrario a modelos generales e insensible a los argumentos de las partes, es el derecho de la época en que las decisiones derivan de revelaciones hechas por el oráculo. (Swedberg, 2005)

Por su parte, en el derecho sustancialmente irracional, las decisiones se producen mediante criterios fundados en consideraciones prácticas y éticas sobre cada caso (Trubeck, 1972, p. 748). Además, Weber (2004b) afirma que: «(...) en la medida en que la decisión esté determinada por valoraciones totalmente concretas de cada caso, sean de naturaleza ética emocional o política, en vez de normas generales» (p. 13). La «justicia del cadí» es el ejemplo de derecho materialmente irracional. Weber entendía la «justicia del cadí» como un concepto más amplio que el de la justicia administrada por el juez musulmán local. Según el autor, este concepto representaba la idea de juicio conforme al sentido de equidad del juez, sin considerar las reglas. (Swedberg, 2005)

En tercer lugar, en el derecho sustancialmente racional, las decisiones se dan mediante leyes o criterios, pero el sistema de derecho, al estar anclado en un pensamiento exterior, depende de la posibilidad de que se comprendan los principios que orientan el pensamiento que le sirven de fundamento (Trubeck, 1972). En este punto, Weber alude a las leyes islámica y china. El poder teocrático y el poder patrimonial impusieron una forma sistematizada de derecho influenciada por elementos que pertenecen, por ejemplo, a la religión y la ideología política. Aunque esos sistemas se relacionen con principios fijos, no reconocen ningún límite 
al derecho y su fin es la concreción de ideales éticos, políticos o religiosos, lo que significa una racionalización material del derecho. O, mejor dicho, al contrario de los dos primeros, la adhesión a principios fijos caracteriza el sistema como racional, pero la idea de concreción de valores religiosos, éticos y políticos hace suponer una racionalización material, y no formal, del derecho. (Kronman, 2009)

La cuarta y última modalidad de derecho, que se sitúa en otro nivel respecto de las anteriores, es la del derecho formalmente racional. Se trata del derecho moderno legislado (Swedberg, 2005). Los códigos civiles derivados del derecho romano y que se fundan en las enseñanzas pandectistas constituyen un ejemplo de derecho formalmente racional. (Wieacker, 1996, pp. 348 y ss.)

La categoría que nos interesa es la del derecho formalmente racional. Para intentar entender lo que para Weber es derecho formalmente racional hay que tener en cuenta que, para él, solo los sistemas que se desarrollaron a partir del derecho romano y que fueron moldeados por la ciencia jurídica pandectista son capaces de reflejar, con un grado de intensidad significativo, conductas y métodos de naturaleza formal y racional (Kronman, 2009). Como pondera Anthony Kronman (2009), el elevado grado de racionalidad formal de estos códigos se explica por el hecho de que se basaron en la «interpretación lógica del sentido» y tenían una naturaleza muy sistemática, de modo que respetaban los cinco postulados elaborados por Weber: «i) que cada decisión jurídica concreta sea la «aplicación» de una proposición jurídica abstracta a una «situación factual» concreta; ii) que deba ser posible, en todos los casos concretos, derivar la decisión de proposiciones jurídicas abstractas mediante lógica jurídica; iii) que el derecho deba constituir verdadera o virtualmente un sistema de proposiciones jurídicas «sin lagunas», o deba, al menos, ser tratado como si fuera un sistema sin lagunas; iv) que todo lo que no pueda ser «interpretado» racionalmente en términos jurídicos también es jurídicamente irrelevante; y v) que toda acción social de seres humanos siempre deba ser vista como una «aplicación» o «ejecución» de proposiciones jurídicas o una «infracción» de ellas, dado que la «inexistencia de lagunas» en el sistema jurídico tiene que derivar en una «ordenación jurídica» sin lagunas de toda conducta social. (pp. 120-121)

Es interesante señalar como Weber observó que el abandono de la justicia del oráculo - en el que la voluntad humana no tenía relevancia - y la prevalencia de un derecho formalmente racional trajeron consigo la necesidad de justificar la decisión, de lo que deriva, en este contexto, la previsibilidad. Como afirma Kronman (2009), si una persona que soluciona conflictos puede alegar que habla en nombre de Dios o de un poder transcendente, puede existir poca presión para que argumente los motivos de la decisión, puesto que ella misma es un oráculo. No obstante, cuando los casos los soluciona un hombre y no poderes oraculares, existe una gran necesidad práctica de justificación. Esto significa que admitir que el ser humano es responsable de la decisión no solo introdujo a la necesidad de justificación, sino que, antes bien, la hizo posible.

El «desencantamiento del derecho»-que no puede confundirse con la categoría del «desencantamiento del mundo» (a este respecto, se puede profundizar con $O$ desencantamento do mundo - Todos os passos do conceito em Max Weber, de Antônio Flávio Pierucci), en la medida en que significa tan solo el paso del poder de juzgar de lo divino o transcendental a lo humano, asume una especial relevancia cuando el derecho pasa a ser formalmente racional. Y es ahí donde surge la necesidad de que la decisión se demuestre de forma racional $y$, junto a ella, de una especie de previsibilidad dotada de sentido. (Kronman, 2009, p. 129)

No obstante, para Weber, la idea de previsibilidad es mucho más amplia y solo puede comprenderse si se percibe lo que él entiende 
por sistema jurídico o, más concretamente, por los conceptos que, según él, lo sostienen, a saber: los conceptos de integridad y claridad organizativa. Como señala Kronman (2009), un orden jurídico es íntegro solo si no hay, en principio, acciones sociales que escapen a su alcance y si no contiene lagunas u omisiones; y tiene claridad organizativa si los principios que lo sostienen son «nítidamente claros y se aplican de modo autoconsciente». Esto quiere decir que, para Weber, cuanto más íntegro y organizativamente claro sea un determinado ordenamiento jurídico más previsibles serán las consecuencias de las acciones sociales llevadas a cabo a su amparo.

Por tanto, esto indica que la idea de previsibilidad, para Weber, no se desvincula de la idea de sistema jurídico y, por ende, es una noción relativa, en la medida en que puede variar en función de que el sistema jurídico sea más o menos íntegro o claro. Consciente de ello, Kronman (2009) señala que, como demuestra el common law inglés, puede lograrse una cierta previsibilidad - tal vez hasta un grado significativo de ella - sin construir un verdadero sistema jurídico. Sin embargo, la previsibilidad máxima solo puede lograrse cuando las reglas del orden jurídico hubieran sido organizadas de un modo integral y claro en términos conceptuales. Por mayor que sea su previsibilidad, siempre es posible que un sistema jurídico sea más previsible por medio de su sistematización. (p. 138)

No existe identidad entre racionalidad formal del derecho y previsibilidad, dado que la previsibilidad es una consecuencia de un sistema jurídico a pesar de su mayor o menor racionalidad. La previsibilidad es objetivo de un sistema dotado de integridad y claridad organizativa, pero puede derivar de un sistema menos racional o incluso de un derecho formalmente irracional, como es el caso, según Weber, del primitivo common law inglés. Debe recordarse que, de acuerdo con la concepción weberiana, en el common law, el grado de racionalidad jurídica es significativamente menor y de una modalidad distinta a la de los sistemas europeos continentales (Weber, 2004b).

De este modo, se llega a lo siguiente: considerando que Inglaterra es la cuna del capitalismo y allí el calvinismo se proyectó de forma muy intensa, ¿cómo se explica la conclusión de Weber de que el common law inglés es un derecho formalmente irracional o no dotado del mismo grado de racionalidad que el derecho continental europeo? ¿Habría hecho Weber una lectura equivocada de la relación entre religión y capitalismo? ¿Se podría decir que Weber había comprendido erróneamente el common law inglés o la historia de Inglaterra? O, simplemente, ¿el sistema de precedentes obligatorios no tenía nada que ver con la racionalidad formal del derecho?

\section{EL LLAMADO «PROBLEMA DE INGLATERRA»}

El argumento de que la obra de Weber tendría una contradicción o una equivocación surgió, fundamentalmente, a partir de un ensayo de David Trubeck, titulado Max Weber on Law and the Rise of Capitalism, publicado en 1972, en la Wisconsin Law Review. En dicho ensayo, Trubeck se refiere al artículo de un alumno suyo, Jerold Guben, titulado 'The England Problem' and the Theory of Economic Development, presentado en el Program in Law and Modernization de Yale Law School.

Trubeck alega que Weber equipara racionalidad jurídica a previsibilidad (o calculabilidad) y entiende que esta última no se da en el common law, de modo que Inglaterra sería una excepción a la teoría de que hay una relación entre calculabilidad y capitalismo o una excepción a la idea de que la racionalidad formal y la calculabilidad necesariamente se dan juntas.

If these contrasting positions indicate that Weber had no clear image of English history in mind, they also reflect his concern with the issue of legal calculability and his tendency to equate it with one mode of legal thought-a mode of thought which clearly was not well 
developed in England. His constant temptation was to maintain the key importance of calculability, and deal with England either as an exception to the theory that legal calculability and capitalism are related, or as an exception to the idea that logically formal rationality and calculability necessarily go together. (Trubeck, 1972, p. 748)

Trubeck advirtió que algunos observadores (aunque, en una nota de pie de página, solo cite el trabajo de su alumno Jerold Guben, The England Problem and the Theory of Economic Development). Habrían dicho que Inglaterra desarrolló un sistema de derecho racional antes incluso de que naciera el capitalismo y que el gran defecto del análisis de Weber estaría en la equivocada distinción que hizo entre el common law inglés y el derecho continental europeo.

Some observers have argued that England did develop a truly «rational» legal system before the rise of capitalism, and that the major flaw in Weber's analysis was the false distinction he drew between English and continental law. (Trubeck, 1972, p. 748)

Sally Ewing, en el ensayo Formal justice and the spirit of capitalism: Max Weber's sociology of law, publicado en Law and Society Review (1987), rechaza la idea de que Weber habría sostenido que un alto grado de racionalidad jurídica sería esencial para el desarrollo del capitalismo, demostrando que, en realidad, Weber habría admitido que, para el desarrollo del capitalismo, bastaría con un «derecho» capaz de facilitar las transacciones comerciales y garantizar la previsibilidad.

For Weber, the «legal order» that was relevant to the rise of capitalism was not a particular type of legal thought but a social order in which law facilitated capitalist transactions by contributing to the predictability of social action. (...) Thus, according to Weber, the legal order that was essential to the growth of capitalism was a contractual one that limited patriarchal discretion and protected its subjects' rights to establish contractual rela- tions and to mobilize the coercive apparatus to enforce those contracts. By thus protecting and enforcing a set of social relations, law became explicitly relevant to economics. It was, in other words, «a complex of actual determinants of human conduct». It made no particular difference whether those relations were defined by a logically formal system or a more informal common law system. To the extent that each system defended the freedom of contract and protected guaranteed rights, the capitalist economic order could thrive. This brings us back to the question about the relationship between types of legal thought and the rise of capitalism. If one concentrates, as Rheinstein did, on legal thought itself, then according to Weber's ideal types common law would be considered «substantively irrational», while civil law would be classified as «logically formally rational» (Weber, 1954: xlii). But if one is concerned not with legal thought but with empirical validity, then Weber quite clearly set out the historical conditions that in England gave birth to a legal system that was particularly well suited to the demands of the bourgeoisie for guaranteed rights and formal justice, the characteristics that distinguish a bourgeois, or liberal, legal system from all those that preceded it. In this sense the common law system, with its «formal rational administration of justice. (p. 498-499, sin cursiva el original)

Swedberg también analizó el «problema de Inglaterra». El sociólogo sueco sostiene que Trubeck se equivoca cuando afirma que, en la obra de Weber, existe una identidad necesaria entre previsibilidad y un grado elevado de formalismo lógico o racionalidad formal. Advierte que Weber deja claro que los grupos burgueses exigían que el sistema jurídico fuera previsible y que la previsibilidad es completamente compatible con un grado reducido de racionalidad formal. Recuerda que Weber afirma que el common law inglés, aunque no esté dotado de racionalidad formal, es previsible. Asimismo, argumenta que en la formulación 
de Trubeck sobre el problema de Inglaterra está implícita una visión muy estrecha de la relación entre capitalismo y derecho, puesto que, para que el capitalismo racional exista, no es suficiente previsibilidad y un alto grado de racionalidad formal, sino que también se exige que haya reglas jurídicas sofisticadas relativas al gran número de instituciones económicas avanzadas, en particular, contratos y empresas económicas, lo que Weber también reconoce.

El principal argumento de Swedberg está en que Trubeck habría cometido un error al ver en Weber una identidad necesaria entre la previsibilidad y un alto grado de racionalidad jurídica formal. Este error, de hecho, fue anticipado en el apartado anterior cuando se señala que la previsibilidad es objetivo de un sistema dotado de integridad y claridad organizativa, pero que puede derivar de un sistema menos racional o incluso de un derecho formalmente irracional. Como afirma Anthony Kronman, la instauración de un modo de producción capitalista eficiente no presupone el nivel máximo de previsibilidad que puede alcanzar la racionalización formal del derecho, de modo que no hay contradicción entre la afirmación de Weber sobre la menor racionalización del derecho inglés y el desarrollo capitalista de Inglaterra.

A la luz de esta interpretación, la aparente tensión entre la afirmación de Weber de que el «derecho y la administración formalmente racionales» son un requisito previo para lograr el mayor grado posible de previsibilidad en la acción económica y su afirmación de que el capitalismo se desarrolló en Inglaterra a pesar de la irracionalidad del common law simplemente desaparece: solo existe una contradicción si se compara el grado máximo de previsibilidad jurídica que puede alcanzar mediante la racionalización formal y el grado mínimo exigido para el estabelecimiento inicial de un sistema de producción capitalista eficiente. (Kronman, 2009, p. 189)

Sin duda, de la argumentación de Weber no solo se puede obtener el sentido de que el common law inglés, aunque no contenga el mismo grado de racionalidad que el derecho europeo continental, era previsible, sino que también se deduce de fragmentos de la obra de Weber que claramente lo afirman, como el referido por Swedberg. Hubert Treiber (s.f.), al tratar el «problema de Inglaterra» según Weber, señala:

The peculiar nature of modern capitalism, especially its technical and economic substructure, requires that success be calculable, and law figures as one means to assure this. However - and this is decisive to the argument - in England and Germany the chances that law and adjudication would be rendered calculable depended on different premises. (...) Despite the rationalization differential between England and Germany with respect to the formal qualities of law, legal proceedings were predictable in both places due to the predictability of the judges, though this may have been assured in different ways. (pp. 841-842)

Para comprender el motivo por el que Weber no vio racionalidad jurídica formal en el derecho inglés primitivo, es necesario observar que el common law, al no preocuparse con la abstracción, no impulsaba la elaboración de principios generales. Tait (1843) y Austin (1991) recuerdan que parte de la doctrina inglesa de finales del siglo XVIII y principios del XIX, descontenta con la falta de racionalidad y previsibilidad del common law, aprobaba el derecho escrito. No se podían producir «conceptos generales», ya que, es a partir de los casos que surgen reglas concretas, que se diferenciaban en función de criterios externos. Reglas de este tipo, aunque sean numerosas, no pueden tener pretensión de «integridad», que, como se ha visto, junto con la claridad organizativa, caracterizaba el ideal de sistema jurídico weberiano. (Kronman, 2009, p. 139)

Sin embargo, para Weber, esto no significaba que el common law inglés no estuviera dotado de algún grado de previsibilidad. Weber admite que la previsibilidad puede lograrse 
no solo mediante un sistema dotado de principios generales y, por ello, capaz de alcanzar la integridad de las situaciones imaginables. En 2009, Kronman afirma claramente, al aludir a la discusión de Weber, que, aunque el orden jurídico carezca de integridad y claridad organizativa, puede lograrse un grado suficientemente elevado de previsibilidad «si los responsables de la administración de las reglas comprenden y respetan los acuerdos contractuales y los criterios basados en el derecho consuetudinario que definen la mayor parte de las operaciones comerciales». (p. 187-188)

Weber también considera que el stare decisis (el sistema de precedentes obligatorios) es un elemento importante para lograr la previsibilidad. Al respecto, afirma que «Y también para el formalismo jurídico hay válvulas de escape. En el ámbito del derecho privado, common law y equity son, sin duda, en gran medida, «formalistas» en la aplicación práctica, ya en virtud de la vinculación a precedentes» (Weber, 2004b, p. 150). Cabe destacar en este contexto el término «formalismo» es sinónimo de previsibilidad. Además, Kronman lo reconoce de forma expresa al aludir al contraste que Weber hace entre el derecho basado en el oráculo y la decisión judicial del common law, que, como necesita justificación, según Weber, tiende a hacer el orden jurídico más previsible:

En realidad, a menos que supongamos que la elaboración de precedentes [se refiere a la fundamentación del precedente] y la regla del stare decisis aumenten la previsibilidad de los resultados jurídicos de modo significativo, es difícil explicar la contribución positiva del sistema jurídico inglés al desarrollo, en Inglaterra, de una economía capitalista racional basada en el intercambio de mercado, una forma de organización económica que, según Weber, exige la aplicación previsible de un conjunto estable de reglas jurídicas. (Kronman, 2009, p. 135)

En vista de que la fundamentación es un requisito para la racionalidad del sistema de pre- cedentes, es evidente que la contribución a la previsibilidad y, en consecuencia, al desarrollo del capitalismo, se identificó con el stare decisis, es decir, la creencia justificada y racional de que la administración de la justicia no dejaría desamparado al emprendedor. Adviértase que Kronman no solo dice que el stare decisis contribuyó a la previsibilidad de «modo significativo», sino que también afirma que, sin el stare decisis, sería «difícil explicar» la contribución positiva que el common law hace al desarrollo del capitalismo.

De este modo, se puede afirmar que el stare decisis fue un importante elemento de equilibrio para la falta de sistematicidad del common law, que contribuyó notablemente a la previsibilidad y, con ello, a la atenuación de la falta de racionalidad jurídica formal del derecho inglés en términos weberianos.

\section{EL SISTEMA DE PRECEDENTES COMO MEDIO DE GARANTIZAR LA PREVISIBILI- DAD DEL DERECHO}

Los valores calvinistas dieron lugar a un comportamiento racional que contribuyó al desarrollo del capitalismo y exigió un derecho racional y previsible. Esto quiere decir que los valores y la cultura de un pueblo pueden y deben relacionarse con la racionalidad del derecho y la administración de la justicia. Esta primera idea es muy importante, en la medida en que, más adelante, se quiere relacionar la cultura del brasileño con la irracionalidad en la distribución de la justicia y la falta de un sistema de precedentes.

Por otro lado, Weber no identificó racionalidad jurídica formal con previsibilidad, sino que, por el contrario, vio en el stare decisis un mecanismo capaz de propiciar previsibilidad a un derecho formalmente irracional, sin que con ello se comprometiera la idea de que, aunque el common law no gozaba de la misma racionalidad que el derecho continental europeo, fue capaz de garantizar, mediante el sistema de los precedentes obligatorios, un grado de previsibilidad que permitió el nacimiento del capitalismo. 
La alegación de Trubeck (1972, p. 748) de que la tesis de Weber habría generado una incoherencia al admitir que Inglaterra, cuna del capitalismo, tenía un derecho formalmente irracional, no resiste al argumento de que Weber nunca identificó racionalidad jurídica formal y previsibilidad y, además, vio en el stare decisis un medio capaz de garantizarla, lo que habría permitido el desarrollo del capitalismo también en un derecho que careciera de racionalidad formal.

Está claro que Weber, al comparar el common law con el derecho continental europeo, admitía la racionalidad formal de este según su forma de ser en aquel momento histórico, y cabe recordar que Weber se hallaba en particular ante el positivismo científico, el conceptualismo alemán, el cognitivismo interpretativo y el logicismo en la aplicación del derecho. Esto quiere decir que, como se verá más adelante, la evolución de la teoría de la interpretación, el impacto del constitucionalismo y la transformación del propio concepto de derecho hicieron surgir una nueva racionalidad jurídica en el civil law, que, por ende, puede exigir y convivir con un sistema de precedentes obligatorios.

Además, el common law, al no gozar de la misma racionalidad formal que el derecho legislado, habría adoptado el stare decisis como medio para equilibrar su poca racionalidad y previsibilidad. Reafirmar que el common law no se identifica con el stare decisis es algo que obviamente no tiene que evidenciarse mediante la obra de Weber.

To a historian at least any identification between the common law system and the doctrine of precedent, any attempt to explain the nature of the common law in terms of stare decisis, is bound to seem unsatisfactory, for the elaboration of rules and principles governing the use of precedents and their status as authorities is relatively modern, and the idea that there could be binding precedents more recent still. The common law had been in existence for centuries before anybody was very excited about these matters, and yet it functioned as a system of law without such props as the concept of the ratio decidendi, and functioned well enough. (Simpson, 1973, p. 77)

Si bien, la oportunidad que Weber ofrece para demostrar que el stare decisis es un instrumento para lograr la previsibilidad en un derecho en el que se percibe una menor racionalidad que el del derecho de la época del positivismo científico tiene una gran relevancia para señalar el carácter imprescindible de un sistema de precedentes obligatorios en un derecho como el brasileño contemporáneo, en el que con mucha frecuencia se deciden casos iguales de modo diferente, sin dar importancia a la previsibilidad, valor moral indispensable para que el hombre se desarrolle y requisito necesario para la racionalidad económica.

\section{REFERENCIAS}

Austin, J. (1911) Lectures on jurisprudence, or the philosophy of positive law [Conferencias sobre jurisprudencia, o la filosofía del derecho positive] (5a ed., Vol. 2). Londres: John Murray.

Bentham, J. (1843) Truth versus Ashhurst; or law as it is, contrasted with what it is said to be. The works of Jeremy Bentham [Verdad Vs. Ashhrust: la ley como es, contrastada con lo que se dice que es. Las obras de Jeremy Bentham] (Vol. 5). Edinburgh: William Tait.

Biéler, A. (2012) O pensamento econômico e social de Calvino [El pensamiento económico y social de Calvino]. São Paulo: Editora Cultura Cristã.

Buarque De Holanda, S. (1995) Raízes do Brasil [Raíces de Brasil]. São Paulo: Companhia das Letras.

Corwin, E. (s.f.) The establishment of judicial review [El establecimiento del control difuso]. Michigan Law Review, 9 (2).

Dicey, A. (1950) Introduction to the study of the law of the constitution [Introducción al studio del derecho de la Constitución] (10. ${ }^{\mathrm{a}}$ ed.). London: Macmillan. 
Ewing, S. (1987) Formal justice and the spirit of capitalism: Max Weber's sociology of law [Justicia formal y el espíritu del capitalismo: La sociología del derecho de Max Weber]. Law and Society Review (21).

Faria, J. (2009) Prólogo de «Max Weber», de Anthony Kronman. Rio de Janeiro: Elsevier.

Goodhart, A. (1934) Precedent in English and Continental law. [Precedente en inglés y derecho continental]. Law Quaterly Review, 50.

Guben, J. (1972) The «England Problem» and the Theory of Economic Development [El «problema inglés» y la Teoría del Desarrollo Económico]. Yale Law School Program in Law and Modernization.

Hazard Jr., C. (1985) Reflections on the substance of finality [Reflexiones sobre la esencia de la finalidad]. Cornell Law Review, 70.

Kaplow, L. (1986) An economic analysis of legal transitions [Un análisis económico de las transiciones legales]. Harvard Law Review, (99).

Kronman, A. (2009) Max Weber. Rio de Janeiro: Elsevier.

Landes, D. (1999) The Wealth and Poverty of Nations: Why Some Are So Rich and Some So Poor [La riqueza y la pobreza de las naciones: ¿Por qué algunos son tan ricos y otros tan pobres]. New York: W. W. Norton.

Lee, T. (2000) Stare decisis in economic perspective: an economic analysis of the Supreme Court's doctrine of precedent [Stare decisis desde una perspectiva económica: un análisis económico de la doctrina de precedentes de la Suprema Corte]. North Carolina Law Review, (78).

Levinson, S. (1988) Constitutional Faith [Fe constitucional]. Princeton: Princeton University Press.

Locke, J. (1989) Second Treatise of Government [Segundo tratado de Gobierno]. Hackett: Indianápolis.
Marinoni, L. (2013) Precedentes obrigatórios (3. ${ }^{a}$ ed.). São Paulo: Ed. Revista dos Tribunais.

Martínez, F. (2003) La ética protestante y el espíritu del constitucionalismo. Bogotá: Universidad Externado de Colombia.

Michelman, F. (1986) Justification (and justifiability) of law in a contradictory world. Nomos XXVIII: Justification [Justificación (y justificabilidad) del derecho en un mundo contradictorio. Ley XXVIII: Justificación]. New York University Press, 71. New York.

Pierucci, A. (2005) O desencantamento do mundo - Todos os passos do conceito em Max Weber [El desencanto del mundo - Todos los pasos del concepto en Max Weber]. São Paulo: Editora 34.

Rosenfeld, M. (2001) The rule of law and the legitimacy of constitutional democracy [El estado de derecho y la legitimidad de la democracia constitucional]. Southern California Law Review, 74(5).

Simpson, W. (1973) The common law and legal theory [El common law y la teoría jurídica] (J., Horder, Ed.). Oxford essays in jurisprudence. Oxford: Clarendon Press.

Souza, J. (2006) Comentários à obra «A gênese do capitalismo moderno» [Comentarios a la obra: «La génesis del capitalismo moderno»]. São Paulo: Ática.

Sunstein, C. (1993) The partial constitution [La Constitución parcial]. Cambridge: Harvard University Press.

Swedberg, R. (2005) Max Weber e a ideia de sociologia econômica [Max Weber y la idea de la sociologia económica]. Rio de Janeiro: Ed. UFRJ.

Treiber, H. (s.f.) «Elective affinities» between Weber's sociology of religion and sociology of law [«Afinidades electivas» entre la sociología de la religion de Weber y la sociología del derecho]. Theory and Society, 14. 
Trubeck, D. (1972) Max Weber on Law and the Rise of Capitalism [Max Weber sobre el derecho y el auge del capitalismo]. Wisconsin Law Review.

Weber, M. (2004) A ética protestante e o «espírito» do capitalismo [La ética protestante y el «espíritu» del capitalismo] (Antônio Flávio Pierucci, Ed.). São Paulo: Companhia das Letras (Originalmente publicado em 1905).

Weber, M. (2009) Economia e sociedade. [Economía y sociedad](Vol.1). Brasília: Editora UnB.
Weber, M. (2004b) Economia e sociedade, [Economía y sociedad](Vol.2), Brasília: Editora UnB.

Wieacker, F. (1996) Privatrechtsgeschichte der Neuzeit unter besonderer Berücksichtigung der deutschen Entwicklung [Historia del derecho privado en los tiempos modernos con especial consideración al desarrollo alemán] (2. ${ }^{\text {a ed. }}$ ) Göttingen: Vandenhoeck \& Ruprecht.

Wood, G. (1998) The Creation of the American Republic: 1776-1787 [La creación de la República Americana]. North Carolina: The University of North Carolina Press. 